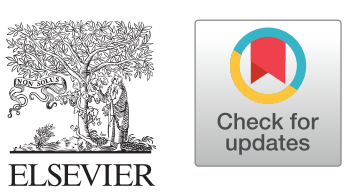

CJC Open 2 (2020) 244-248

\title{
Original Article \\ Practice Variation in Establishing the Adequacy of Beta-Blockers as an Antiarrhythmic Agent in School-Aged Children and Adolescents
}

\author{
Hilal Al Riyami, MD, ${ }^{\text {, } \ddagger}$ Arif Hussain, MD, ${ }^{\mathrm{b},}$ Andrew Warren, MD, FRCPC, ${ }^{\mathrm{b}}$ and \\ Santokh S. Dhillon, MD, FRCPC ${ }^{b}$ \\ ${ }^{a}$ Division of Cardiology, Department of Pediatrics, University of Alberta, Edmonton, Alberta, Canada \\ ${ }^{b}$ Division of Cardiology, Department of Pediatrics, Dalhousie University/Izaak-Walton-Killam, Health Centre, Halifax, Nova Scotia, Canada
}

\begin{abstract}
Background: Beta-blockers (BBs) are commonly prescribed to manage arrhythmias in children and adolescents without any standardised approach to establish BB adequacy. We invited all Canadian pediatric cardiologists to participate in an anonymous survey to understand practice variation in the assessment of BB adequacy in school-aged children and adolescents with arrhythmia or the potential for arrhythmia.

Methods: An electronic survey approved by the Institutional Ethics Board was distributed by e-mail to 96 Canadian pediatric cardiologists who had been active in practice for at least 1 year. Incomplete surveys were excluded.

Results: Forty-one cardiologists (43\%) responded to all questions in the survey. Thirteen cardiologists (32\%) reported always assessing BB adequacy, 17 (41\%) did so only for specific arrhythmias, and 11 (27\%) reported never performing such an assessment. A total of 19 cardiologists (46\%) and 18 cardiologists (44\%) reported using Holter monitoring and exercise testing, respectively, to assess beta receptor
\end{abstract}

Beta adrenergic receptor blockers, commonly known as "betablockers" (BBs), are often used as first-line therapy for common arrhythmias in children. BBs reduce the adrenergic stimulation of cardiac pacemaker cells and conduction tissue, and reduce the dispersion of repolarization over the myocardium. ${ }^{1,2}$ Effective arrhythmia control with $\mathrm{BB}$ depends on the degree of beta receptor blockade. ${ }^{1}$ Therefore, an appropriate

Received for publication January 27, 2020. Accepted March 12, 2020.

Ethics Statement: This research has adhered to IWK Institutional Ethics guidelines.

${ }^{\ddagger}$ These authors contributed equally to this work.

Corresponding author: Dr Santokh S. Dhillon, Department of Pediatrics, Dalhousie University/IWK Health Center, 5850/5980 University Ave., Halifax B3K 6R8, Canada. Tel.: +1-902-470-6956; fax: +1-902-470-6616.

E-mail: santokh.dhillon@iwk.nshealth.ca

See page 247 for disclosure information.

\section{RÉSUMÉ}

Contexte : Les bêtabloquants (BB) sont couramment prescrits pour traiter les arythmies chez l'enfant et l'adolescent, en l'absence de méthode standardisée permettant d'établir le caractère adéquat du traitement par ces agents. Nous avons invité tous les cardiologues pédiatriques canadiens à participer anonymement à une enquête visant à rendre compte de la variabilité observée en pratique dans l'évaluation du caractère adéquat du traitement par BB chez l'enfant d'âge scolaire ou l'adolescent atteints d'arythmie ou susceptibles de l'être.

Méthodologie : Un questionnaire électronique approuvé par le comité d'éthique en établissement a été distribué par courriel à 96 cardiologues pédiatriques canadiens en exercice depuis au moins un an. Les questionnaires partiellement remplis ont été exclus.

Résultats : Parmi les participants, 41 cardiologues (43\%) ont répondu à toutes les questions de l'enquête. D'après les réponses obtenues, 13 cardiologues (32\%) évaluent toujours le caractère adéquat du traitement par BB, 17 (41 \%) l'évaluent uniquement en présence de

clinical strategy is to administer a dose of BB that effectively suppresses cardiac arrhythmia without causing unwanted side effects such as bradycardia or hypotension. It is known that different doses of $\mathrm{BB}$ are required to achieve the same therapeutic effect in different patients with the same disease. ${ }^{3,4}$ For example, arrhythmia-related deaths reported in children receiving apparently adequate doses of $\mathrm{BB}$ raise the possibility of inadequate beta receptor blockade as a possible explanation for apparent treatment failure. ${ }^{5,6}$ Yet, we have observed even within our own practice group that BBs are often prescribed without establishing the adequacy of beta blockade using standardized criteria. While some practitioners use serial Holter monitors, others use exercise tests or resting electrocardiograms (ECGs) to establish the adequacy of beta receptor blockade. $^{7,8}$

Given this inhomogeneity, the objective of this study was to better understand the practice variation among Canadian 
blockade adequacy. Thirteen cardiologists $(32 \%)$ considered BB therapy adequate if Holter demonstrated a $20 \%$ decrease in heart rate (HR) from baseline, and 10 respondents (24\%) defined adequate BB therapy using exercise testing as a $20 \%$ decrease in maximal HR or blood pressure from baseline.

Conclusion: Despite wide variation in practice, Holter monitoring and exercise testing are commonly used methods to measure the adequacy of BB therapy. There are no standard criteria, but the majority (56\%) reported using a $20 \%$ decrease in HR or blood pressure from the pretreatment state as a criterion for adequate BB therapy in children and adolescents with arrhythmia or the potential for arrhythmia.

pediatric cardiologists in the assessment of the clinically desired adequacy of BB prescribed for prophylaxis or treatment of arrhythmias in school-aged children and adolescents.

\section{Methods}

A questionnaire was distributed electronically to actively practicing pediatric cardiologists in Canada. The names and e-mail addresses of all 96 participant cardiologists were obtained from the websites of the Canadian Cardiovascular Society and Canadian Pediatric Cardiology Association. Two reminders were sent at 2-week intervals. To avoid duplicate responses, potential participants were requested not to respond if they had already completed the survey once. Participants responded anonymously and voluntarily with consent, without any provision to trace back the response. The questionnaire consisted of 3 questions about demographics and 8 questions about the frequency, type of tests, and threshold of measuring adequacy of BB use for treatment and prevention of arrhythmia in children older than 5 years of age (Supplementary Appendix S1). The Research Ethics Board at the Izaac Walton Killam Health Centre (Research Ethics Board \#1021083) approved the study.

Data were analyzed using the Statistical Package for the Social Sciences, Version 2009 (IBM Corp., Chicago, IL) and Microsoft Excel (Microsoft Corp., Redmond, WA). Descriptive data are presented as frequencies and percentages. Percentages reported represent the percentages of the responses to each individual question.

\section{Results}

The survey was sent to 96 pediatric cardiologists. Forty-one completed the survey, representing a $43 \%$ response rate. Of those responding, $40(98 \%)$ were in academic practice and 23 $(56 \%)$ were practicing for more than 15 years. certains types d'arythmies et 11 (27\%) ne l'évaluent jamais. Au total, parmi les cardiologues interrogés, 19 (46\%) et 18 (44\%) affirment avoir recours respectivement à l'électrocardiographie (ECG) ambulatoire et à l'épreuve d'effort pour évaluer le caractère adéquat du blocage des récepteurs bêta. Ainsi, 13 cardiologues (32 \%) jugent que le traitement par BB est adéquat si l'enregistrement ECG ambulatoire démontre une diminution de $20 \%$ de la fréquence cardiaque (FC) maximale par rapport à la valeur de référence, et 10 cardiologues (24\%) estiment qu'il en est de même si le résultat obtenu à l'épreuve d'effort démontre une diminution de $\mathbf{2 0} \%$ de la FC maximale ou de la pression artérielle par rapport aux valeurs de référence.

Conclusion : Malgré de grandes variations observées en pratique, I'ECG ambulatoire et l'épreuve d'effort sont des méthodes couramment utilisées pour mesurer le caractère adéquat du traitement par BB. II n'existe pas de critères standard, mais la majorité (56\%) des répondants ont indiqué qu'une diminution de $20 \%$ de la FC ou de la pression artérielle par rapport aux valeurs de référence obtenues avant le traitement constitue un critère du caractère adéquat du traitement par BB chez l'enfant ou l'adolescent atteints d'arythmie ou susceptibles de l'être.

Nadolol and atenolol were reported as the 2 most commonly prescribed agents in children aged more than 5 years. In considering assessment methods for BB therapeutic adequacy, some practitioners used more than 1 assessment method, depending on the indication for BB use. As a result, the types of assessment reported are not mutually exclusive.

\section{Initial assessment}

Thirteen of 41 respondents to this question (32\%) reported performing an objective assessment of the adequacy of BB to guide therapy in all patients, and 17 of $41(41 \%)$ did so only for specific indications such as long QT syndrome, catecholaminergic polymorphic ventricular tachycardia, channelopathies, malignant arrhythmias, symptomatic patients, and atrial ectopic tachycardia, or if the therapy was not effective despite therapeutic dosing levels. Of note, 11 (27\%) reported never attempting to measure $\mathrm{BB}$ therapeutic adequacy (Fig. 1).

Nineteen respondents (46\%) and 18 respondents (44\%) reported using Holter monitoring and exercise testing, respectively, and 11 respondents $(27 \%)$ used resting heart rate (HR) on serial ECG to measure the adequacy of BB therapy. A further 4 respondents (10\%) reported "by history," "casual exercise in clinic," "depends upon age or condition," and "device interrogation" as measures to assess BB adequacy.

\section{Longitudinal reassessment}

Twelve cardiologists of the 19 respondents to this question (63\%) reported annual Holter monitoring to longitudinally reassess the adequacy of the $\mathrm{BB}$, and 2 respondents $(10 \%)$ repeated a Holter every 6 months. Likewise, 8 of 18 cardiologists (44\%) reported repeating exercise stress testing yearly, and 3 cardiologists (17\%) reported repeating exercise stress testing every 6 months for this purpose. Of those reporting serial ECG use, 7 of $11(63 \%)$ performed serial ECGs every 6 months to assess $\mathrm{BB}$ adequacy, and the remaining cardiologists used annual ECGs, or ECGs with each clinic visit. 


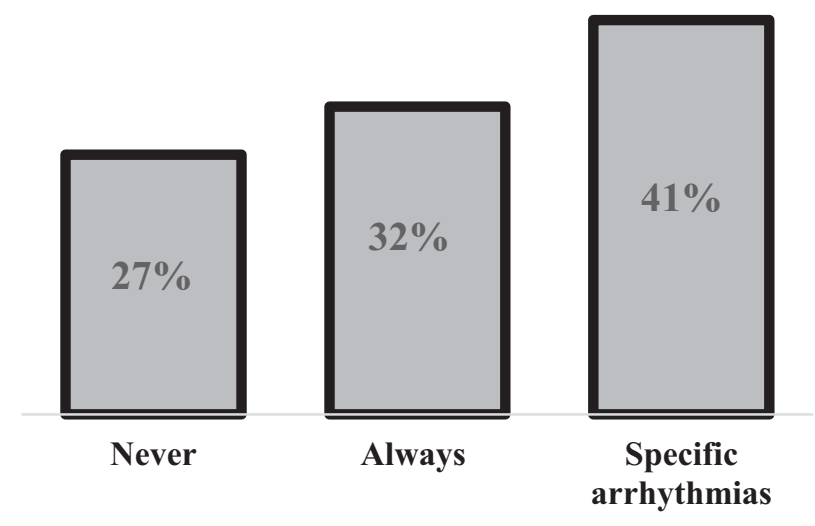

Total responses $=41$

Figure 1. Perceived need among pediatric cardiologists to measure adequacy of beta-blocker (BB) therapy.

\section{"Baseline" definitions and accepted threshold for adequate beta receptor blockade: Holter monitoring}

Of a total of 19 responses, 10 cardiologists (53\%) and 5 cardiologists $(26 \%)$ reported using the average and maximum $\mathrm{HR}$ on pretreatment Holter as the baseline, respectively. The rest of the respondents reported using predicted average HR for this purpose when pretreatment Holter monitoring was not performed.

The majority $(13 / 19 ; 68 \%)$ of the respondents using Holter monitoring reported a $20 \%$ decrease in HR from baseline as their threshold for adequate beta receptor blockade. The remaining $6(32 \%)$ reported this threshold to be a decrease of $10 \%$ or $30 \%$ or a decrease of 20 or 30 beats in average or maximum HR or combination of these 2 criteria.

\section{"Baseline" definitions and threshold for adequate beta receptor blockade: Exercise testing}

Ten of the 18 respondents using exercise testing to check the adequacy of $\mathrm{BB}$ therapy (53\%) reported using the maximum $\mathrm{HR}$ at peak exercise on pretreatment exercise testing as a baseline, whereas $8(47 \%)$ used the maximum predicted HR at peak exercise for age to define baseline. Likewise, 10 of 18 (53\%), considered a decrease in HR or BP at peak exercise by at least $20 \%$ from baseline as a threshold for adequate beta receptor blockade.

A minority of practitioners reported using other thresholds: Three (17\%) used a $10 \%$ decrease and $2(11 \%)$ used a $30 \%$ decrease in HR or BP from baseline; the remainder of respondents used a reduction in HR or systolic BP from baseline by 20 to 30 points.

\section{"Baseline" definitions and threshold for adequate beta receptor blockade: ECGs}

Serial ECGs to define BB therapeutic adequacy were also used by 11 respondents (27\%). Eight respondents (73\%) reported using a $20 \%$ reduction in HR from pretreatment ECG as an indication for adequate beta receptor blockade.

\section{Discussion}

This study is the first to assess the variation in clinical practice of establishing BB dose adequacy in school-aged children and adolescents with documented arrhythmia or the potential for arrhythmia. The results show that approximately one-third of cardiologists reported assessing patients for adequacy of BB therapy only for specific arrhythmias. In contrast, approximately one-third (32\%) always assessed the adequacy of $\mathrm{BB}$ therapy, irrespective of the indication for $\mathrm{BB}$ use. Of note, $27 \%$ of cardiologists reported that they did not assess $\mathrm{BB}$ dose adequacy at all. These results reflect significant variation in the perceived need for BB dose adequacy assessment among pediatric cardiologists. Similar variation in practice is also seen in cardiologists' propensity to test and treat. $^{9}$

The question of whether BB dose adequacy assessment is necessary is important. Previous studies did not find BB therapy entirely effective in preventing arrhythmic deaths or breakthrough cardiac events in patients with long QT syndrome and catecholaminergic polymorphic ventricular tachycardia, respectively. ${ }^{5,10}$ Although our results were not confined to patients with potentially life-threatening arrhythmias as in the study by Moss et al., ${ }^{5}$ our results nonetheless expose a potential patient care risk. Patient-specific characteristics such as race, genetic heterogeneity, and differences in underlying pathology are known to influence the response to standard dosage $\mathrm{BB}$ differently. ${ }^{3,5,11}$ For example, in a multivariate analysis, African American children $(<18$ years of age) were less likely to have a blunted HR response ( $<90 \%$ of predicted HR for age) to BB compared with white children. ${ }^{3}$ Such differences suggest that standard dosing based on weight may not achieve the expected or desired therapeutic results in individual children.

Our survey also found that when cardiologists do use a form of monitoring for the effectiveness of BB therapy, Holter and exercise testing are the tests most commonly used. Most suggested a yearly reassessment. ECGs were also used frequently, and most often, these were done at least every 6 months. Again, though, there was considerable heterogeneity observed with respect to the choice and frequency of performance of tests proposed. This likely reflects the current lack of evidence around specific care pathways for these and other patients within the pediatric cardiology community. Others have examined the frequency of test performance in patients with congenital heart disease and found similar variation. ${ }^{12}$

Complicating consideration of the method to assess therapeutic $\mathrm{BB}$ adequacy is the fact that cardiologists responding to our survey also defined "baseline" state differently, regardless of the method of assessment used. There is a relative dearth of literature in this area as well. Shah and Carter ${ }^{7}$ considered a $20 \%$ decrease in maximum $\mathrm{HR}$ on exercise testing as adequate evidence of the adequacy of the $\mathrm{BB}$ therapy. ${ }^{7}$ In contrast, Wong et al. ${ }^{13}$ used a reduction in peak treadmill HR of 30 beats/min at peak work load as a measure of adequate $\mathrm{BB}$ effect. When considered together, these are consistent with the choices made by the majority of cardiologists in our study.

In routine clinical practice, BBs are usually prescribed at a standard weight-based dose without pursuing any objective 
assessment of the degree of beta receptor blockade with resting ECG, Holter monitor, or exercise testing. ${ }^{5,14}$ Our study clearly demonstrates the variation in the perceived need for and methods of defining the level of adequacy of BB therapy among Canadian prescribers. As such, it is imperative that this aspect of treatment be examined with a view to defining whether "adequacy testing" makes a meaningful difference to patient outcomes. If so, then standardized criteria should be devised to assess the BB effect. Such criteria would allow for individualized BB doses that can be titrated to the target effect, and thus potentially offer better protection against arrhythmia while avoiding significant side effects.

\section{Limitations}

This study has several limitations. First, although comparable to other surveys of physicians, ${ }^{15}$ the response rate of the survey was relatively low (43\%), and almost all responses were from academic pediatric cardiologists. Therefore, it is possible that the information obtained through this survey might not reflect the practice of most pediatric cardiologists in Canada. Likewise, the variation in practice noted in this survey reflects what was reported by the respondents. It may or may not reflect actual clinical practice because of recall bias. Further, the list of potential participants was chosen from the professional society of pediatric cardiologists in Canada. Although this society will include the majority of practitioners, membership is not mandatory, and the sample may not fully reflect the views of the entire Canadian pediatric cardiology community. We were also unable to estimate the number of practitioners using both Holter and exercise testing to assess degree of beta receptor blockade. This might be important information from a financial and resource use point of view. Because of the anonymous nature of the survey, it was not possible to link responses to a single respondent. Some of the questions were nonspecific without any reference to a specific patient population or arrhythmia requiring BB therapy, which might also partially explain the heterogeneity in respondents' responses and our inability to identify the types of arrhythmia for which testing of $\mathrm{BB}$ adequacy was considered beneficial by the practitioners. The survey was only written in English without French translation, so some cardiologists in Canada might have not participated.

\section{Conclusion}

Although there is wide variation in practice, with a substantial minority of practitioners performing no adequacy testing, exercise testing and Holter monitoring are commonly used by Canadian pediatric cardiologists to measure the adequacy of BB therapy in children. Of those using testing, $56 \%$ of respondents use a $20 \%$ decrease in HR or BP from pretreatment state as a marker of adequate beta receptor blockade. However, the lack of a consistent approach and the potential for different responses to BB therapy by different individuals highlight a need for further studies to establish standardized, practical criteria for BB adequacy that can be applied to all patients.

\section{Acknowledgements}

The authors thank the Canadian Cardiovascular Society and Canadian Pediatric Cardiology Association for providing contact information for all the registered practicing cardiologists.

\section{Funding Sources}

The Division of Pediatric Cardiology at the Izaac Walton Killam Health Center provided funding to conduct this survey.

\section{Disclosures}

The authors have no conflicts of interest to disclose.

\section{References}

1. Coumel P, Leclercq JF, Escoubet B. Beta-blockers: use for arrhythmias. Eur Heart J 1987;8(Suppl A):41-52.

2. Stramba-Badiale M, Goulene K, Schwartz PJ. Effects of betaadrenergic blockade on dispersion of ventricular repolarization in newborn infants with prolonged QT interval. Am Heart J 1997;134: 406-10.

3. Taylor B, Moffett BS, Krenek M, Valdes SO, Kim J. Race contributes to beta-blocker efficacy in pediatric patients with arrhythmias. Pediatr Cardiol 2014;35:641-4.

4. Shin J, Johnson JA. $\beta$-Blocker pharmacogenetics in heart failure. Heart Fail Rev 2010;15:187-96.

5. Moss AJ, Zareba W, Hall WJ, et al. Effectiveness and limitations of betablocker therapy in congenital long-QT syndrome. Circulation 2000;101: 616-23.

6. Ackerman MJ. The long QT syndrome: ion channel diseases of the heart. Mayo Clin Proc 1998;73:250-69.

7. Shah M, Carter C. Long QT syndrome: a therapeutic challenge. Ann Pediatr Cardiol 2008;1:18-26.

8. Chatrath R, Bell CM, Ackerman MJ. Beta-blocker therapy failures in symptomatic probands with genotyped long-QT syndrome. Pediatr Cardiol 2004;25:459-65.

9. Lucas FL, Sirovich BE, Gallagher PM, Siewers AE, Wennberg DE. Variation in cardiologists' propensity to test and treat is it associated with regional variation in utilization? Circ Cardiovasc Qual Outcomes 2010;3: 253-60.

10. Hayashi M, Denjoy I, Extramiana F, et al. Incidence and risk factors of arrhythmic events in catecholaminergic polymorphic ventricular tachycardia. Circulation 2009;119:2426-34.

11. Goldenberg I, Bradley J, Moss A, et al. Beta-blocker efficacy in high-risk patients with the congenital long-QT syndrome types 1 and 2: implications for patient management. J Cardiovasc Electrophysiol 2010;21: 893-901.

12. Rathod RH, Jurgen B, Hamershock RA, et al. Impact of standardized clinical assessment and management plans on resource utilization and 
costs in children after the arterial switch operation. Congenit Heart Dis 2017;12:768-76.

13. Wong JA, Gula LJ, Klein GJ, et al. Utility of treadmill testing in identification and genotype prediction in long-QT syndrome. Circ Arrhythm Electrophysiol 2010;3:120-5.

14. Vincent GM, Schwartz PJ, Denjoy I, et al. High efficacy of beta-blockers in long-QT syndrome type 1: contribution of noncompliance and QTprolonging drugs to the occurrence of beta-blocker treatment "failures". Circulation 2009;119:215-21.
15. VanGeest JB, Johnson TP, Welch VL. Methodologies for improving response rates in surveys of physicians: a systematic review. Eval Health Prof 2007;30:303-21.

\section{Supplementary Material}

To access the supplementary material accompanying this article, visit CJC Open at https://www.cjcopen.ca/ and at https://doi.org/10.1016/j.cjco.2020.03.008. 